\title{
Innovation of Performance Management of Enterprise Human Resource in the Era of Big Data
}

\author{
Haipin Li \\ Shandong Huayu University of Technology, Dezhou 253000, China
}

Keywords: Large data, enterprise, human resources, performance management, innovation, strategy.

\begin{abstract}
Ultimately, the war of modern enterprises is the war between talents and talents. For the development of enterprises, a large number of companies introduce high-quality talents at all costs. In the era of big data, given the flourishing formation technology, that provides new opportunities for enterprises to recruit and assess talents. It has become an important direction for enterprises to think about how to use big data to help the innovation of enterprise human resources performance management. This article makes an in-depth analysis about the human resource performance management in the era of big data. The main part of the study is in five aspects: the importance of enterprise human resources performance management, the influences on performance management of enterprise human resource, the positive impact on performance management of enterprise human resource for big data, the existing problems on performance management of enterprise human resource, and the innovation strategy of performance management of enterprise human resource in the era of big data.
\end{abstract}

\section{Introduction}

The word "performance" always appears, when it comes to whether a company's welfare benefits are perfect, the promotion channels are unimpeded, and people's performance scores are reasonable. Performance management is not only linked to employee benefits, but also has a huge correlation with employee's career and companies` development. At the same time, many high quality enterprises will have the model of human resource performance management in order to attract more talents. However, there are many problems in the current performance management of enterprise human resources, which requires enterprises to vault and reform. This article makes an in-depth analysis of these problems as well as provides the corresponding innovation strategy for the relevant practitioners to refer.

\section{The importance of enterprise human resources performance management}

\subsection{The performance appraisal encourages the staff to achieve better development.}

In modern enterprises, it often does equal pay for equal work. This way in the wages determination is beneficial to the corporate harmony and the fair in payment of wages to some extent. Some staff working very hard and do most of the tasks in the process of work. But sometimes some staff attaches no importance to work. In this case, it is the same price between hard-working staff and non-striving staff which largely discourage the hard-working staff. Therefore, according to the results obtained by the staff and the completion of the work goal to carry out performance appraisal. Excellent personnel can reward but unqualified personnel can't. In this way, it can fully excite staff's job enthusiasm and promoted company development to a large extent.

\subsection{Performance appraisal can promote the accuracy of company's recruitment.}

Companies in the development process need a large number of recruiters to complete the work. Work ability and expertise of the recruiters are the key factors to affect the development of enterprises. Therefore, it is very important to have an excellent enterprise HR. So how do we study the quality of the HR recruiters? Through performance appraisal of new staff, the performances evaluations can represent the level of staff recruited by HR, and can also reflect the expertise. Of 
course, the results of assessment can also provide feedback to the recruitment in the future. Enterprises can find more talents for business development from this feedback information. And it also can summarize the professional qualities of talents for different and promote the accuracy of recruitment.

\subsection{Regulating management behavior.}

The human factor is the important factor of effect in the current enterprise management. The proportion of people's role in enterprise management is very large. It was the key role of among enterprises management. Therefore, firms' development, management, and even decision of some big projects need people to do it. Once a person has less formal management behavior, it will have a great impact on the firms' development. Through performance appraisal, it is clear to define the responsibilities of different people. By using performance appraisal, we can test different people's decisions and follow-up as well as the behavior of staff in the management process. Regulating management behavior to a large extent and reducing an enterprise operating risks.

\section{The influences on performance management of enterprise human resource}

\subsection{Whether the business process is reasonable.}

Performance management requires a large number of media. Only through different media, it can be implemented to all aspects. The business process is the most important medium of performance management in the. Only if the business process is reasonable enough, can performance management have a complete medium to get a lot of accurate data, so that we can ensure the integrity and accuracy of performance management.

\subsection{Whether the organization is perfect enough.}

Reasonable performance management mechanism makes reasonable classification according to different divisions and different work of personnel. Finally, the enterprises carry out it with such classification. But now, there are many unreasonable classifications of enterprises in the organization. Different departments may operate the same task, and blame each other. In the process of performance management, the implementation of the relevant responsibilities can't find the corresponding departments, but many departments want the results. Finally, performance management not only loses the original intention for the enterprise development, but also generates confusion in the enterprise. Therefore, whether the organization is perfect enough that affects the performance management of enterprise human resource.

\subsection{Whether the design goal of the enterprise performance management system is clear.}

It is necessary to clear the goal of enterprise performance management when doing human resources performance management. If the design objective of enterprise performance management system is not clear enough, the direction of enterprises will be confused. The end result of which is that the performance management system is ineffective or even has a counteraction. As some enterprises will regard performance appraisal as the main way of performance management when they make the goals of the performance management system, and the purpose is to supervise the employees' work. The purpose of that is monitoring the staff. Of course, it can raise the working efficiency of staff to a certain extent. But it will lead to employee think enterprises distrust them and feel no attachment. Eventually, enterprises may be set back on low morale. Therefore, enterprises have to define what is standard for development, when making the design goal of the performance management system. That will strengthen the development of the enterprise.

\section{The positive impact on performance management of enterprise human resource for big data}

\subsection{Unleashing more human potential and improve staff motivation.}

In the traditional performance management of enterprise human resource, often a single performance management model is used to record and analyze the employees' performance. This process leads to that human factors have a big effect on the results of human resource performance 
management. And the data which have collected by single human resource performance are very little and single. Being unable to form persuasive data, it can not promote the future development of enterprises. However, through the introduction of large data, enterprises can take advantages of large data to improve the performance management of enterprise human resources. It has accuracy and a less influence from human factor about conducting human resource performance analysis with a large number of data and feedback from employees from different jobs and different times. The results of the analysis are not only accurate, but also influenced by human factors. Large data can also be used to predict the future development of employees to unleash more human potential and improve staff motivation.

\subsection{To optimize the organization structure and benefit the planning of the reserved talents.}

It is impossible to solve the problem which we mention in the above content about the confusion of enterprise organization by using the traditional human resources performance management model. But through the introduction of big data, different organizations, different departments, different staff and different work contents can be reasonably divided by big data. With a comparatively modest, time-limited way, it optimizes organization significantly. Moreover, the staff in many departments may not be suitable for the current work and have unexplored potential. Those things that are hard to distinguish before can be quickly achieved through big data, which is more conducive to talent planning and makes the company's talent structure more reasonable. In the present time of information explosion, the winner of the enterprise is those who have advantage of getting data, analyzing data, using data.

\subsection{Using large data to build an effective model of talent data management.}

In the traditional evaluation of enterprise human resources performance management, it is based on subjective judgment of the managers and his deviation is large. However, through the application of large data, all kinds of information in human resource management can be collected and analyzed. The application of big data can not only help conduct the fairest analysis for the results of human resource management, but also provides the most accurate judgments for the future development direction of enterprise human resource management. Furthermore, it gives the most reasonable development direction for managers.

\section{The existing problems on performance management of enterprise human resource}

\subsection{Performance appraisal has strong subjectivity and lack of objective data support.}

In the process of performance appraisal for the staff, it's basically about the opinions of the leaders in charge. It is likely to have several problems in such a performance assessment model. One is the results of the performance appraisal are not fair. A lot of employees do different work in different stages, but the leaders often select one area as an evaluation criterion. It is cheaper for some unbalanced development of the staff on the performance appraisal process. But the staffs who have balanced development have been greatly affected. The other is that prejudices of the leadership may lead to outstanding talent's outflows. If taking opinions of the leaders as the main criteria in performance appraisal, there will be some situation where leadership plays favoritism or even acts officiously. After all, personal evaluation has to be biased. So given enough time, this will lead to that channel promotion has obstruction and some excellent talents leave the company. Eventually, outstanding talents will lose.

\subsection{The performance management has become formulaic.}

In many enterprises, they attach great importance to make regulations of the enterprise human resource management mechanism. But in the process of implementation, it has become formulaic. On the one hand, it is due to that enterprises lack the data to analysis talents. The data analysis of human resource performance evaluation under big data application is not enough, which can not provide enough help for enterprise to make decision. And gradually they will lose their status. On the other hand, it is because many enterprise leaders value theory more than practice in the process of performance management. Lacking practical experience and copying the large data performance 
management model of other enterprises. It ultimately lead to that the performance management has become formulaic.

\subsection{Managers do not dig deep enough on data.}

The results of performance management have not been fully applied. With the introduction of large data, a large amount of data will be obtained in the process of enterprise human resource performance management. Some of these data are for some aspect, some of the data are comprehensive, and they will also give a trend prediction. But managers are often paying attention to a single aspect of data. Performance management results have not been fully applied.

\section{The innovation strategy of performance management of enterprise human resource in the era of big data}

\subsection{To expand the source of data collection.}

The source of data collection should be expanded with great degree, applied in performance management of enterprise human resource. The data of enterprise human resources performance management often come from three sources. The first is the objective basic data of the enterprise human resources. This part is mainly to record the age, education, content and department of the employees. These records try to ensure accuracy and the data should involve much basic information so as to have more references for later data analysis. The second is to record the analysis data which is the changes of the enterprise human resources. This needs to include the completion rate of the staff, the cycle of the recruitment in a position, and the loss of the staff, etc. They are all important sources of data collection. It is easy to analyze enterprise position setting, the salary treatment, and the performance management whether are reasonable. The third is to record the analysis data of the quality of human resources. This part is mainly to record the efficiency of work, attendance and results of the staff. These are important data for analyze the quality of human resources, and are also the main assessment criteria for the promotion of employees.

\subsection{To innovate methods of human resources performance management.}

Firstly, we should set up a reasonable goal. To design human resource performance management, we should base on the development of enterprises, prompt employee' activity, and regard channel promotion for excellent employees. Secondly, in the performance evaluation model, we should give up the traditional one, use the large data to realize the comprehensive performance evaluation model, and provide the diversified reference data for the assessment of the enterprise staff. Finally, the performance evaluation index should be set up reasonably, and make the assessment standards formulated according to the different types of enterprises. For example, some service companies turn the rate of customer satisfaction and complaint into the assessment standards of the enterprise. Some construction companies should take the success rate and the satisfaction as the performance evaluation index.

\subsection{Using the Internet technology to improve the efficiency of enterprise human resource performance management.}

The Internet contains a large number of data which can improve the efficiency to a certain extent. In the same way, it is also able to use the features of Internet technology to make the evaluation process more timeliness.

\section{Summary}

The competitions in enterprises are attributed to that of talent! If we want to obtain and retain talent, we must rely on reasonable model of the enterprise human resources performance management. It is the area where many modern business lack and is the main reason why enterprise talent loss. All important decisions and ideas are put forward and implemented by talents. So enterprises need to have enough talents to develop. In the era of big data, enterprises have new opportunities to improve the quality of human resources performance management and contribute to the enterprises development. 


\section{References}

[1] Rong Fan The innovation research of the performance management of enterprise human resources in the era of big data. [J]. Modern Marketing, 2017, (11).

[2] Zhaoe Yang. The innovation analysis of the performance management of enterprise human resources in the era of big data.[J]. Shangqing, 2017(26)

[3] Yufei cheng. The innovative research of analyzing the performance management of enterprise human resources in the era of big data.[J]. CHINA BUSINESS, 2017, (05): 38-39.

[4] Yin Liu. The innovative exploration of the performance management of enterprise human resources in the era of big data.[J]. Economic \& Trade Practice, 2017, (05).

[5] Xixi Liang. The innovation research of the performance management of enterprise human resource in the era of big data.[J]. Manager`Journal, 2017, (26). 